\title{
Revisão Sistemática da Literatura Nacional: uma Reflexão com Base na Educação Corporativa
}

\section{Systematic Review of National Literature: a Reflection Based on Corporate Education}

\author{
Marcia Lopes de Moraes Sella; Diego Fogaça Carvalho*ab
}

\begin{abstract}
annopar, Programa de Pós-Graduação Stricto Sensu em Metodologias para o Ensino de Linguagens e suas Tecnologias. PR, Brasil. bUniversidade Anhanguera Uniderp, Programa de Pós-Graduação Stricto Sensu em Ensino de Ciências e Matemática. MS, Brasil. *E-mail: diegofocarva@gmail.com
\end{abstract}

\begin{abstract}
Resumo
O objetivo deste artigo foi realizar uma revisão sistemática da literatura nacional para uma melhor compreensão sobre a Universidade Corporativa - UC e sua configuração como um meio de aprendizagem, não somente no âmbito corporativo, mas também na área acadêmica, bem como as metodologias e procedimentos empregados. Optou-se por uma revisão sistemática da literatura, em que foram coletados artigos científicos na base de dados de Periódicos Capes, no período de 2001 a 2020, com classificação A1 até B2 na área de ensino, pelo sistema de classificações de periódicos do quadriênio 2013-2016. Os resultados apontam que a Universidade Corporativa é um ambiente eficaz em relação à formação profissional de modo geral, principalmente, para desenvolver pessoas nos diversos níveis e operações, sendo também ambiente com inúmeras possibilidades de engajamento e aplicação. Por outro lado, há uma lacuna a ser preenchida e que pode ser explorada para que haja maior parceria entre a Universidade Tradicional e Universidade Corporativa e, assim, promover o potencial existente entre ambas, inclusive, servindo de subsídio para futuras pesquisas, projetos e programas sobre a temática.
\end{abstract}

Palavras-chave: Universidade Corporativa. Treinamento. Aprendizagem Profissional. Formação de Professores

\begin{abstract}
Faced with the era of knowledge and innovation, a tireless search was noticed for qualified professionals to meet the requirements of the time, in order to contribute to the country's economic sustainability. In this sense, the Corporate University, being present in the corporate or academic environment, can train citizens in a strategic and social way for a better performance of their activities. The objective of this research work was to carry out a systematic review of the national literature to stimulate reflection on the relevance of the Corporate University (UC) as a learning tool, not only in the corporate scope, but also in the academic area, contributing to the formation of these professionals. The procedure adopted to conduct the study was a systematic literature review, where scientific articles were collected in the Capes Periodicals database from 2001 to 2020, with classification A and B in the teaching area, by the journals classifications system of the quadrennium 20132016 and, the obtained and synthesized data. The results show that the Corporate University is an effective tool in relation to training in general, mainly to develop people at different levels and operations, being a tool with numerous possibilities for engagement and application. On the other hand, there is a gap to be filled and that can be explored so that there is a greater partnership between the Traditional University and the Corporate University and, thus, promoting the existing potential between the two, including serving as a subsidy for future research, projects and programs on the theme.
\end{abstract}

Keywords: Corporate University. Training. Professional Learning. Teacher training

\section{Introdução}

Diante da era do conhecimento e da inovação se percebe uma busca incansável por profissionais qualificados para atender aos requisitos da época com intuito de contribuir para a sustentabilidade econômica das empresas e do país. Uma das formas como as organizações vêm enfrentando a escassez de profissionais qualificados tem sido por meio da educação corporativa, ou seja, oportunizar aos colaboradores melhorar sua capacidade de operar estrategicamente as funções desenvolvidas e, assim, se manterem em seus postos de trabalho.

De acordo com Filatro (2019), os primeiros focos de educação corporativa surgiram na década de 1950 em organizações como a General Motors, no entanto, a consolidação da Universidade Corporativa (UC) ou Educação Corporativa, aconteceu nos Estados Unidos na década de
1980. No Brasil, a adoção desse conceito ocorreu um pouco mais tarde, na década de 1990. Entre as organizações que aderiram ao sistema de educação estratégica nos moldes de Universidade Corporativa, segundo Eboli (2012), se pode citar a Academia Accor, em 1992, a Universidade Brahma (1995), a Universidade do Hambúrguer, do McDonald's (1997) e várias outras empresas conceituadas no mercado, que buscaram maior competitividade, em um cenário cada vez mais globalizado e, desde então, as competências profissionais, em todas as áreas, têm se configurado uma das maiores exigências.

Nesse aspecto, Filatro (2019 p. 56) menciona: "Para as empresas, a preocupação com a real aplicação das competências desenvolvidas dentro do trabalho e o impacto sobre os negócios são os aspectos mais relevantes", ou seja, as empresas passaram a constituir programas educacionais alinhados às estratégias do negócio, sendo 
uma das metodologias utilizadas para superar os desafios da contemporaneidade, contribuindo para uma lacuna existente na fase escolar e promovendo a sustentabilidade econômica das empresas e do país.

Dessa forma, percebe-se que praticidade e agilidade nos métodos e processos são características fundamentais para a implantação de cursos de formação continuada de modo estratégico em um determinado ambiente, incluindo na área acadêmica.

Tal fato, permite entender as transformações ocorridas para o gerenciamento de pessoas e a real necessidade em conceber o trabalhador como um parceiro, capaz de retornar à organização os benefícios advindos de sua competência, conhecendo sua potencialidade, as vantagens em desenvolvêlo e promover seu senso crítico, por meio de formação continuada.

Tardif (2014), em sua obra, Saberes docentes e formação profissional, levantou alguns questionamentos relacionados à formação, um desses diz respeito se os profissionais do ensino desenvolvem e/ou produzem realmente "saberes" oriundos de sua prática e, em caso positivo, por que, quando, como, de que forma essa produção ocorre?

Para Tardif(2014), é necessário que esses questionamentos sejam realizados, pois demonstra uma preocupação com o desempenho das atividades docentes e isso fortalece o engajamento dos alunos. Essa construção do conhecimento é imprescindível em qualquer área de atuação, seja na corporação de uma empresa ou uma Instituição de Ensino. Para tanto, existe a necessidade de estar constantemente em busca de atualizações e aprendizagens de novos procedimentos que sejam instruídos e construídos por pessoas que saibam utilizar as metodologias adequadas para esses saberes e propósitos.

Nesse contexto, compreendendo a importância da formação profissional, incluindo a formação dos professores, é que pensar a Universidade Corporativa, também com base na perspectiva de Tardif (2014), se faz presente e necessária, sendo um dos caminhos para a continuidade da construção dos saberes, fazendo-se valer no que se refere à construção dessa formação, podendo ser cogitada a parceira com outros agentes internos ou externos à instituição.

Partindo da premissa de que esses mesmos saberes poderão estar presentes na construção para formação de profissionais, via Universidade Corporativa, em construção com outros agentes em sistema de parceria, este estudo tem como objetivo realizar uma revisão sistemática por meio da análise de artigos científicos de origem nacional para melhor compreender a Universidade Corporativa (UC) como um meio de aprendizagem, não somente no âmbito corporativo, mas também na área acadêmica, bem como as metodologias e procedimentos empregados.

\section{Desenvolvimento}

\subsection{Metodologia}

Para atender aos objetivos deste estudo, a formulação do quadro-analítico se baseou no método de pesquisa denominado Análise de Conteúdo. Segundo Bardin (2011), a análise de conteúdo pode ser organizada em: pré-análise; exploração do material e tratamento; e interpretação dos resultados.

Para Bardin (2011), a pré-análise corresponde a fase inicial, um período de intuições, que tem por objetivo sistematizar e operacionalizar as ideias iniciais para conduzir o caminho a ser trilhado nas operações seguintes. $\mathrm{Na}$ sequência, a exploração do material se torna longa e fastidiosa, consistindo em operações de codificação, decomposição ou enumeração e, por fim, o tratamento e interpretação dos resultados obtidos, tendo em mãos resultados significativos e fiéis, em que o analista realiza interpretações, conforme objetivos previstos ou mesmo relacionado às descobertas inesperadas.

$\mathrm{Na}$ sequência, pode-se compreender o processo da pesquisa realizada na prática:

Figura 1 - Modelo de Protocolo Adotado

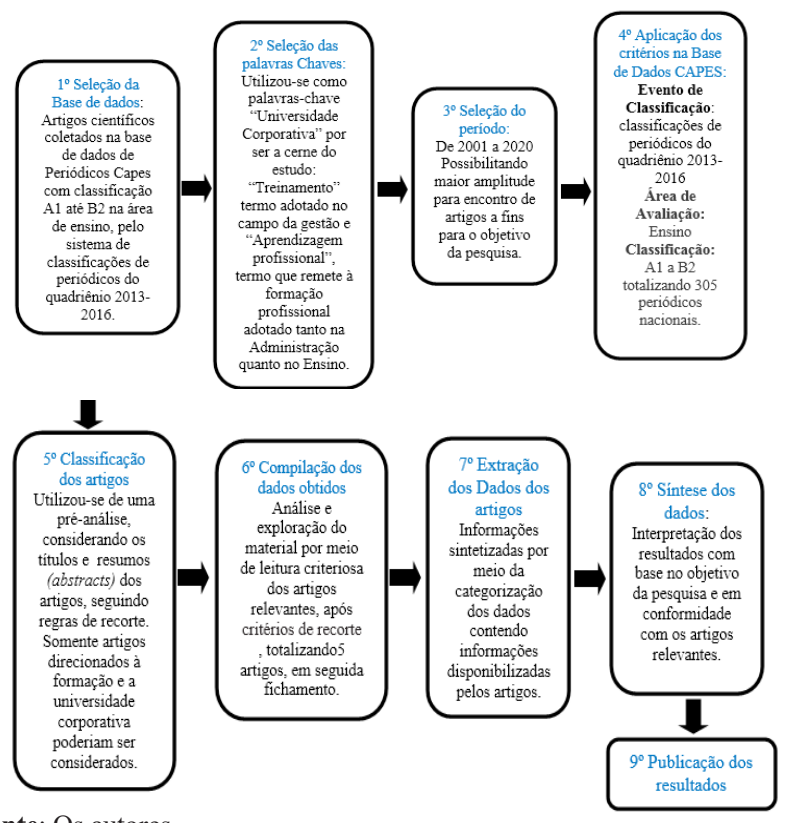

Fonte: Os autores.

Para a seleção dos artigos, alguns critérios foram estabelecidos, entre esses, a presença de algumas palavras consideradas representativas de acordo com o referencial e com os objetivos da pesquisa. O termo "Universidade Corporativa", por ser o cerne do estudo; "Treinamento", um termo utilizado para a formação de pessoas nas organizações e "Aprendizagem Profissional", pois abarca, de forma mais genérica, a formação profissional nas áreas de administração e ensino nos artigos sobre a temática, ou seja, um desafio para busca de artigos nos periódicos relacionadas ao ensino, já que a pesquisa se refere ao sistema de educação estratégica adotado pelas empresas para desenvolver seus talentos humanos e alguns periódicos qualificados na área de ensino são de outras competências, por exemplo, o Qualis da revista de ISSN: 1981-7347, Revista do Instituto Histórico e Geográfico de Sergipe, conforme a Figura 2. 
Figura 2 - Busca realizada de periódicos científicos CAPES ENSINO

\section{Periódicos}

\begin{tabular}{|l|l|l|l|}
\hline ISSN & Título & Área de Avaliação & Classificação \\
\hline $1981-7347$ & REVISTA DO INSTITUTO HISTÓRICO E GEOGRÁFICO DE SERGIPE & ENSINO & B2 \\
\hline
\end{tabular}

Fonte: Dados da pesquisa.

$$
\text { II Início } \triangleleft \text { Anterior } 1 \text { ¿ Próximal Fim DII }
$$

$$
1 \text { a } 1 \text { de } 1 \text { registro(s) }
$$

Os artigos publicados deveriam estar no período temporal de 01 de janeiro de 2001 a 31 de maio de 2020 em Língua Portuguesa. Estabeleceu-se este período temporal, para que houvesse maior probabilidade no encontro de artigos da área organizacional.

A Figura 3 ilustra a planilha utilizada para a busca dos artigos, considerando os periódicos das revistas na base da CAPES.

Figura 3 - Planilha de buscas nos periódicos científicos CAPES

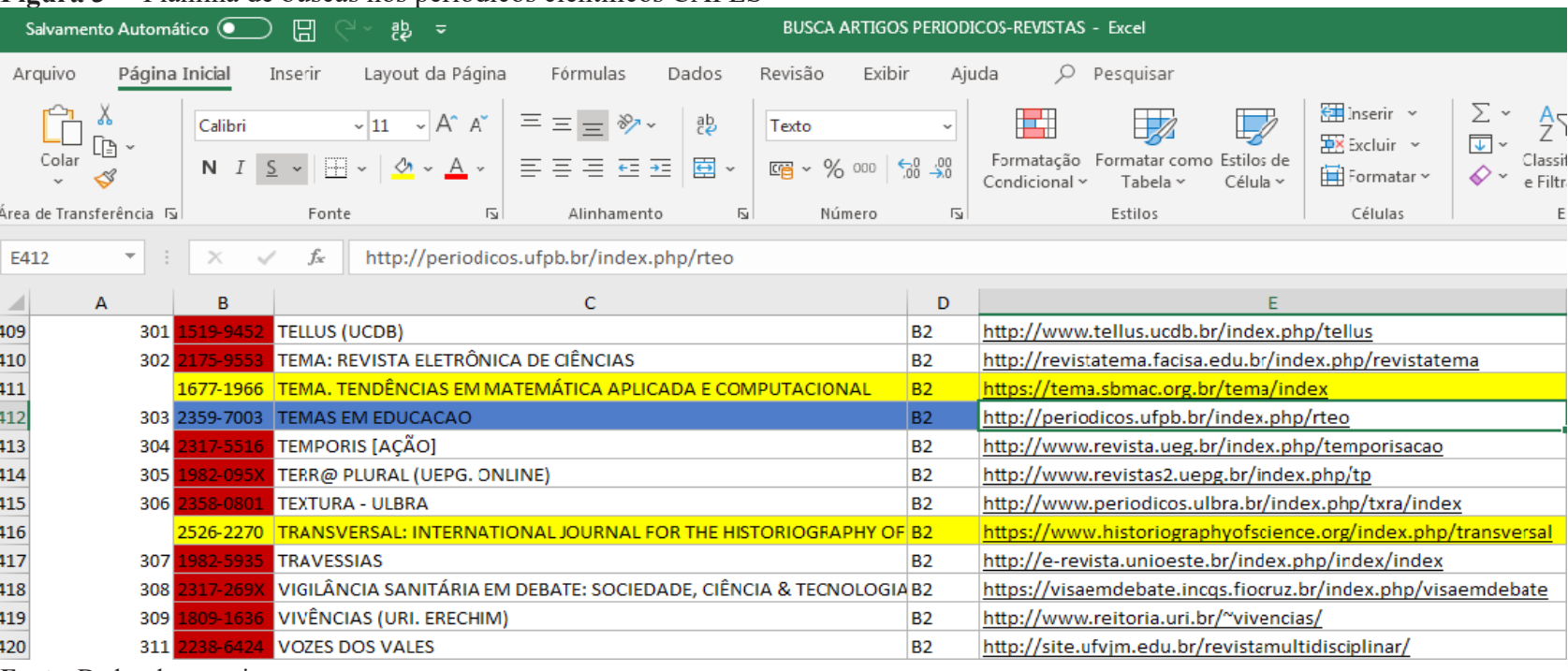

Fonte: Dados da pesquisa.

A planilha contém 419 periódicos no total. Desses, 114 periódicos internacionais foram descartados por não integrarem os objetivos prestabelecidos deste estudo.

Depois de aplicado esses critérios, os dados como ano, título, autores e periódicos dos artigos foram compilados em uma planilha eletrônica. Em seguida, os artigos foram categorizados da seguinte forma: os artigos que relatam estudos sobre Universidade Corporativa, ou seja, que foram implementados nas Instituições de Ensino (área acadêmica) ou Organizações Corporativas (empresas), estariam classificados como validados, e os que não apresentassem correlação com a Universidade Corporativa, seriam inválidos para o estudo proposto. Dessa forma, 293 períodicos pesquisados considerando as palavras-chave: "universidade corporativa" AND "treinamento" OR "aprendizagem profissional", não apresentaram nenhum resultado. Somente 12 periódicos foram satisfatórios para encontro de 16 artigos resultantes das palavraschave. Ainda assim, apenas 5 desses artigos foram realmente relevantes para a proposta da pesquisa, sendo que o objetivo foi compreender a configuração da Universidade Corporativa (UC) como um ambiente de aprendizagem no âmbito corporativo e acadêmico, bem como as metodologias e procedimentos empregados, conforme quadro apresentado na sequência:

\begin{tabular}{|c|c|c|c|}
\hline 2001 & \begin{tabular}{l}
\multicolumn{1}{c|}{ Título } \\
Universidade Corporativa: \\
uma nova estratégia \\
para a aprendizagem \\
organizacional.
\end{tabular} & \begin{tabular}{l}
\multicolumn{1}{|c|}{ Autores } \\
Carvalho e \\
Cruz
\end{tabular} & \begin{tabular}{l}
\multicolumn{1}{r|}{ Revista } \\
Ciência \\
Sempre: \\
Revista da \\
FAPERN \\
\end{tabular} \\
\hline 2003 & $\begin{array}{l}\text { Considerações sobre o } \\
\text { uso da vídeo conferência } \\
\text { como elemento } \\
\text { viabilizador de EAD em } \\
\text { um ambiente multiponto: } \\
\text { o caso da Petrobras }\end{array}$ & $\begin{array}{l}\text { Almeida, } \\
\text { Parisi e } \\
\text { Stamato }\end{array}$ & $\begin{array}{l}\text { Educar em } \\
\text { Revista }\end{array}$ \\
\hline 2007 & $\begin{array}{l}\text { Universidade Corporativa: } \\
\text { (pré)tendência do Ensino } \\
\text { Superior ou ameaça? }\end{array}$ & $\begin{array}{l}\text { Silva e } \\
\text { Balzan }\end{array}$ & $\begin{array}{l}\text { Avaliação - } \\
\text { Revista da } \\
\text { Avaliação } \\
\text { da Educação } \\
\text { Superior }\end{array}$ \\
\hline 2013 & $\begin{array}{l}\text { O processo de construção } \\
\text { da UNESP Corporativa }\end{array}$ & $\begin{array}{l}\text { Bizelli e } \\
\text { Darido }\end{array}$ & $\begin{array}{l}\text { Revista Ibero } \\
\text { Americana de } \\
\text { Estudos em } \\
\text { Educação } \\
\end{array}$ \\
\hline 2016 & $\begin{array}{l}\text { Propostas pedagógicas } \\
\text { no contexto da Educação } \\
\text { Corporativa }\end{array}$ & $\begin{array}{l}\text { Grossi, } \\
\text { Costa e } \\
\text { Souza } \\
\end{array}$ & $\begin{array}{l}\text { Revista temas } \\
\text { em educação }\end{array}$ \\
\hline
\end{tabular}

Quadro 1 - Síntese dos artigos selecionados

Fonte: Dados da pesquisa. 
Neste momento, foram analisados os artigos por meio de uma leitura criteriosa atendendo aos requisitos de Bardin (2011), as potencialidades da UC e sua estrutura nas organizações, bem como a metodologia utilizada para compreender se há um paralelo entre a UC corporativa e a UC tradicional, de modo que se percebam pontos de encontro entre os segmentos. Com base no exposto, a seguir será apresentada uma análise sobre os resultados.

\subsection{Resultados e Discussão}

Não há controvérsias ao se referir à educação como uma fonte geradora de riquezas para a economia e para a sociedade e, com isso, a iniciativa de governantes e dirigentes empresariais em novas formas para atender às demandas do mercado.

Foram várias Reformas na Educação do Brasil, por exemplo, a reforma Capanema de 1942, em reconhecimento ao Ministro Gustavo Capanema, que instituiu um conjunto de Leis Orgânicas da Educação Nacional, com o intuito de promover a subdivisão entre o ensino secundário, cuja intenção era formar as elites, que iriam conduzir o país e o ensino profissional, destinado a formar cidadãos que atendessem às necessidades emergentes da economia industrial e da sociedade urbana, conforme as Diretrizes Curriculares Nacionais Gerais da Educação Básica (BRASIL, 2013).

Em outro momento, A Lei no 11.741 de 16 de julho de 2008, que dispõe sobre as Diretrizes e Bases da Educação Nacional (BRASIL, 2008), por exemplo, redimensionou, institucionalizou e integrou as ações da Educação Profissional Técnica de Nível Médio, da Educação de Jovens e Adultos e da Educação Profissional e Tecnológica.

As mudanças ocorridas há décadas na história da educação, no Brasil, faz refletir sobre o distanciamento social e as desigualdades que se presencia cotidianamente em meio a constantes avanços tecnológicos surgidos ao longo dos anos, em que as informações ficaram obsoletas a cada dia e a presença de riquezas é nítida, contrariando o que apregoa a Constituição da República Brasileira de 1988, Cap. I, Art. $6^{\circ}$, em consonância com os Direitos e Deveres Individuais e Coletivos, assegurando a todo cidadão os princípios básicos, a saber: “[...] São direitos sociais a educação, a saúde, a alimentação, o trabalho, a moradia, o transporte, o lazer, a segurança, a previdência social, a proteção à maternidade e à infância, a assistência aos desamparados, na forma desta Constituição" (BRASIL, 1988, Art. 6º).

Embora haja algum empenho, por parte dos governantes, presencia-se pessoas nas mais variadas condições de pobreza, não possuindo ao menos condições básicas de moradias, que dirá nível escolar adequado para que pudesse transformar sua realidade, defasagem que transcorre às diversas reformas e que, em muitos casos, compromete a vida produtiva e, apesar de a educação ter sido projetada há tempos, apenas uma minoria, possuindo acesso a essa, consegue finalizar seus estudos.
No intuito de reduzir essa defasagem escolar e social, a educação de jovens e adultos (EJA), no geral, formada por trabalhadores mesmo em formação tardia, busca amenizar parte das desigualdades e suas distorções, suprindo uma carência do ensino e redução da exclusão social, formando cidadãos de forma sistemática e continuada, no nível de conclusão do Ensino Fundamental e do Ensino Médio, conforme apregoa a Constituição da República brasileira de 1988, Cap. III, Art. 205\%: "A educação, direito de todos e dever do Estado e da família, será promovida e incentivada com a colaboração da sociedade, visando ao pleno desenvolvimento da pessoa, seu preparo para o exercício da cidadania e sua qualificação para o trabalho" (BRASIL, 1988, Art. 205).

Por muito tempo, o trabalhador foi apenas parte de um processo, uma espécie de engrenagem de uma máquina, diante de uma estrutura verticalizada e centralizadora. Todavia, a busca pela qualificação profissional ficou mais evidente quando as tarefas deixaram de ser mecanizadas e passaram a ser mais complexas, exigindo profissionais capazes de pensar, de decidir e de executar.

A Figura 4 ilustra os processos de aprendizagem na UC nos diversos níveis, atendendo aos objetivos traçados pela organização, sendo a aprendizagem contínua um dos fatores de assertividade, podendo utilizar a aprendizagem ativa e as ferramentas tecnológicas disponíveis.

Figura 4 - Processos da aprendizagem na Universidade Corporativa

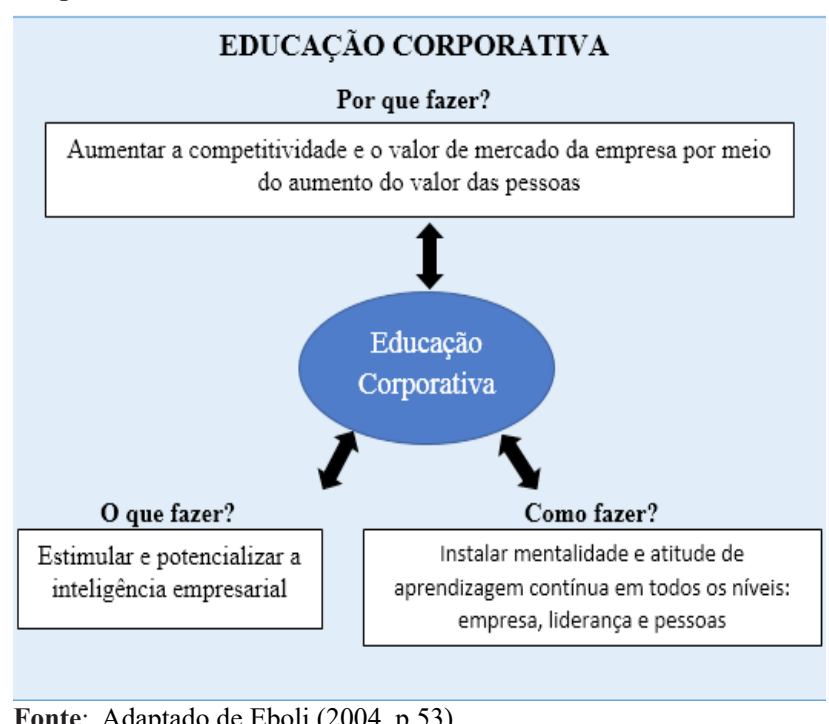

Fonte: Adaptado de Eboli (2004, p.53).

Embora a UC esteja presente nas grandes empresas para a formação e aprendizagem dos colaboradores, alguns autores veem com preocupação o papel da UC incitando uma ameaça para o ensino.

No entanto, o Quadro 2 apresenta as especificidades desses dois segmentos. 
Quadro 2 - Papel das Universidade Tradicionais e das Universidades Corporativas

\begin{tabular}{|l|l|}
\hline \multicolumn{1}{|c|}{ Universidade Tradicional } & Universidade Corporativa \\
\hline $\begin{array}{l}\text { Aprendizagem baseada em } \\
\text { sólida formação conceitual e } \\
\text { universal }\end{array}$ & $\begin{array}{l}\text { Aprendizagem baseada na } \\
\text { prática dos negócios }\end{array}$ \\
\hline Sistema educacional formal & $\begin{array}{l}\text { Sistema do desenvolvimento } \\
\text { de pessoas pautado pela } \\
\text { gestão por competências }\end{array}$ \\
\hline $\begin{array}{l}\text { Ensinar crenças e valores } \\
\text { universais }\end{array}$ & $\begin{array}{l}\text { Ensinar crenças e valores da } \\
\text { empresa e do ambiente de } \\
\text { negócios }\end{array}$ \\
\hline $\begin{array}{l}\text { Desenvolver cultura } \\
\text { acadêmica }\end{array}$ & $\begin{array}{l}\text { Desenvolver cultura } \\
\text { empresarial }\end{array}$ \\
\hline $\begin{array}{l}\text { Formar cidadãos competentes } \\
\text { para gerar o sucesso das } \\
\text { instituições e da comunidade }\end{array}$ & $\begin{array}{l}\text { Formar cidadãos competentes } \\
\text { para gerar o sucesso da } \\
\text { empresa e dos clientes }\end{array}$ \\
\hline Fonte: Eboli (1999, p. 117). &
\end{tabular}

Para Tardif(2014), é necessário que se tenha a preocupação com o desempenho das atividades docentes, oriundas de sua prática. Assim, como acontece em outros segmentos, podendo ser nas indústrias, nos bancos etc., ou seja, em diversas categorias e agentes envolvidos. Para o autor, essa formação continuada contribui para fortalecer o engajamento dos alunos e o professor precisa estar sempre em "movimento", isso significa, estar sempre buscando novas metodologias para sua prática, que pode ser adquirida por meio da sua formação.

Ainda, em sua obra, Tardif (2014 p.230) confirma a importância na obtenção das técnicas para o bom desempenho das atividades e comenta:

[...] um professor de profissão não é somente alguém que aplica conhecimentos produzidos por outros, não é somente um agente determinado por mecanismos sociais: é um ator no sentido forte do termo, isto é um sujeito que assume sua prática a partir dos significados que ele mesmo lhe dá, um sujeito que possui conhecimentos e um saber-fazer provenientes de sua própria atividade e a partir dos quais ele a estrutura e orienta.

Nesse contexto, o pedagogo empresarial poderá participar do processo, sendo corresponsável em áreas estratégicas por meio da produção e disseminação de conteúdos, que contribuirão para resultados positivos, seja para sua própria formação continuada ou para os demais envolvidos, alavancando outros resultados, por exemplo, aumento na qualidade de ensino e desenvolvendo novos métodos de aprendizagem e, consequentemente, fidelizando um número maior de alunos para a adesão de novos cursos, entre outros fatores que contribuirão para o alcance do objetivo estratégico da Instituição de Ensino.

Sabe-se que novos métodos de ensino têm sido utilizados para a formação de pessoas na contemporaneidade, seja na área acadêmica ou no campo profissional, em busca de resultados satisfatórios que atendam às necessidades individuais ou coletivas. Estes novos formatos incluem o ensino híbrido, principalmente, nas Universidades Corporativas, demonstrando a necessidade de profissionais qualificados para o uso das novas metodologias.
Para atender ao objetivo deste estudo, no qual se buscou compreender configurações da Universidade Corporativa (UC) como um meio de aprendizagem no âmbito corporativo e acadêmico, bem como as metodologias e procedimentos empregados, tendo sido possível encontrar somente 12 periódicos satisfatórios para a análise de 16 artigos resultantes das palavras-chave, ainda assim, apenas 5 desses artigos foram realmente relevantes para a proposta da pesquisa, conforme apresentados na sequência:

Carvalho e Cruz (2001) pesquisaram a UC das empresas Brahma, Algare Accor, e identificaram algumas características: o objetivo da UC, na AmBev, foi a aprendizagem organizacional, voltada para prover competência para o atendimento das necessidades de clientes e consumidores, tendo como metodologia de ensino: estrutura modular de aprendizagem e aprendizado em grupo e como instrutores seus líderes (gerentes, diretores e supervisores).

Já a UC do Grupo Algar teve como objetivo difundir os valores e a cultura do grupo e desenvolvimento da liderança. Para isso, as metodologias utilizadas foram: estudos de casos internos, cursos vivenciais com dinâmicas, que estimulassem o pensar e agir dos participantes, tendo como instrutores: associados e consultores externos. Por fim, o Grupo Accor Brasil tem como objetivo a formação de profissionais do grupo, para assegurar o crescimento da empresa e o desenvolvimento do potencial dos seus recursos humanos. A metodologia utilizada implicam atividades lúdicas, exercícios práticos, trabalhos prévios e projetos após o curso e como instrutores: profissionais externos e consultores da academia.

Essas organizações apresentaram uma UC com objetivo predefinido, direcionado para a gestão empresarial e seus instrutores são profissionais especialistas na área empresarial. Assim, como o modelo apresentado de UC nas organizações, a metodologia pode servir de exemplo para Instituições de Ensino na formação continuada de professores, utilizandose das competências e habilidades adquiridas no exercício da profissão na construção de materiais e orientação didática, servindo de instrumento para melhor instruí-los nas atividades do cotidiano.

No caso Petrobras, apresentado por Almeida, Parisi e Stamato (2003), o uso da UC teve como objetivo o aperfeiçoamento de colaboradores do setor de controladoria em parceria com a FIPECAFI/FEA/USP, ofertando o curso em nível de Pós-graduação. A metodologia empregada foi com base aulas presenciais e videoconferência, propondo leituras e desenvolvimento prévio de exercícios e estudos de casos. Os instrutores foram os próprios professores da FIPECAFI/FEA/USP, que já ofertavam o curso ao público externo presencialmente.

Comparando o modelo apresentado pela Petrobras e a pesquisa analisada por Carvalho e Cruz (2001), observa-se que a formação passou a ter um viés acadêmico, considerando a parceria com a Instituição de Ensino FIPECAFI/FEA/USP, 
na qual já ofertava o curso ao público externo e por se tratar de disciplinas generalistas, contribuindo para que o projeto de MBA Controller na organização se concretizasse, no sistema de modalidade semipresencial atendendo às necessidades dos colaboradores e suas limitações.

Já Silva e Bazan (2007) colocam em xeque a existência da UC, traçando um paralelo entre a UC e o ensino tradicional, bem como críticas ao sistema.

As críticas realizadas pelos autores estão pautadas nas influências neoliberais. Para eles, o conhecimento na era da globalização possui foco nas necessidades empresariais, aprisionamento do indivíduo e não sua autonomia. Acreditam, ainda, que há uma grande diferença entre a Universidade Corporativa e Universidade Tradicional, a saber, pela sua estrutura e fins específicos. Consideram a UC um apelo mercadológico não formando o homem em sua totalidade. Segundo os autores, a UC se refere a uma nova faceta do Taylorismo, priorizando exclusivamente os processos produtivos, enquanto a Universidade Tradicional, a começar pela Lei que a rege 9.394 /96, de 20 de dezembro de 1996 (BRASIL, 1996) promove o ensino, a pesquisa e a extensão, favorecendo o desenvolvimento das Ciências em todos os ramos do conhecimento, sendo uma das características que as diferem, indo ao encontro das comparações feitas por Eboli ( 1999 p. 117) sobre as diferenças entre a Universidade Tradicional e Universidade Corporativa, embora a autora não apresente a Universidade Corporativa com este víes negativo, mas sim, como uma modalidade complementar, que favoreça as organizações na completude das competências não adquiridas pela Universidade Tradicional.

Bizelli e Darido (2013) apresentam, em sua pesquisa, o Programa de Educação Corporativa da Universidade Estadual Paulista - UNESPCorp, tendo como objetivo desenvolver o quadro de pessoal da instituição, com foco na aprendizagem organizacional e licitatória. O material foi produzido pela equipe do NEAD e pela TV UNESP em módulos e os encontros no modelo semipresencial.

Para os autores, o período após a revolução industrial se caracteriza pela necessidade de uma nova forma de aprendizagem, constituindo a UC como um novo cenário educacional e difere do Ensino tradicional, que segundo Bizeli e Darido (2013) "um conhecimento holístico, não fragmentado como acontece nos cursos que formam um tipo de profissional específico". Essa abordagem se mostra contrária as ideias de Silva e Bazan (2007) ao criticarem a Universidade Corporativa, dando ênfase ao ensino tradicional.

Por fim, Grossi, Costa e Souza (2016) tiveram como objetivo discutir a necessidade e importância em estabelecer um projeto pedagógico para fundamentação das ações de aprendizagem desenvolvidas pelas Universidades Corporativas à semelhança do que se faz no ambiente acadêmico. Como metodologia, realizou um estudo sobre projetos pedagógicos de Universidades Corporativas brasileiras e, por fim, um estudo de caso para pesquisar o projeto pedagógico de uma instituição financeira.

De acordo com os autores, o processo cognitivo acontece também, além dos espaços acadêmicos, sendo o local de trabalho, um dos locais favoráveis para a aprendizagem ao considerar que cada indivíduo pertencente a determinado grupo e carrega consigo conhecimentos intrínsecos e, ao ser disponibilizado a seus pares, consistirá em informações relevantes para a organização e seus processos.

Para os autores, o projeto pedagógico no âmbito das universidades corporativas possui a mesma função que no contexto acadêmico - estabelecer referencial teórico e metodológico para a prática educativa.

Considerando a análise dos estudos exploratórios realizados pelos autores em relação ao projeto pedagógico nas UC pesquisadas, puderam perceber que dois dos projetos se preocuparam com a formação abrangente do sujeito, indo além da simples compreensão das tarefas, além disso, o estímulo para que o colaborador fosse protagonista do processo de ensino e aprendizagem, despertando a curiosidade e aprendizagem contínua, indo na mesma direção da proposta deste estudo, mostrando que a integração de metodologias acadêmicas podem se fazer presentes nas organizações de forma a vir "somar" em novas experiências.

\section{Conclusão}

Com o intuito de responder a proposta deste estudo sobre a compreensão da Universidade Corporativa (UC) como um meio de aprendizagem, não somente no âmbito corporativo, mas também na área acadêmica, bem como as metodologias e procedimentos empregados, pôde ser observado que a Universidade Corporativa é eficaz em relação à formação de modo geral, principalmente, para desenvolver pessoas de diversos níveis e operações, por meio de procedimentos com inúmeras possibilidades de engajamento e aplicação. No entanto, pôde-se perceber também que os agentes formadores da UC, na maioria dos casos, são integrantes da própria organização ou ainda especialistas e/ou consultores, levando a compreender que há uma lacuna a ser preenchida e que pode ser melhor explorada para que haja maior parceria entre a Universidade Tradicional e Universidade Corporativa e, assim, promover o potencial existente entre as duas.

O grande desafio para a universidade tradicional é o de unir forças com as UCs, conciliando os objetivos do colaborador e suas experiências adquiridas, da corporação e da Instituição de Ensino, em uma parceria a três, benéfica para todas as partes envolvidas.

\section{Agradecimentos}

Coordenação de Aperfeiçoamento de Pessoal de Nível Superior - CAPES - Código de Financiamento 001. Aos docentes do Programa de Pós-Graduação em Metodologias para o Ensino de Linguagens e suas Tecnologias - Unopar. 


\section{Referências}

ALMEIDA, L.B.; PARISI, C.; STAMATO, M. Considerações sobre o uso da videoconferência como elemento viabilizador de EAD em um ambiente multiponto: o caso da Petrobras. Educ. Rev., n.21, p.1-18, 2003.

BARDIN, L. Análise de conteúdo. São Paulo: Edições 70, 2011.

BIZELLI, J.L.; DARIDO, M.C. O processo de construção da Unesp Corporativa. Rev. Iberoam. Estud. Educ., v.8, n.2, p.513528, 2013.

BRASIL. Ministério da Educação. Lei de Diretrizes e Bases da Educação (2008): Lei n ${ }^{\circ}$ 11.741/08, de 16 de jul. de 2008. Brasília: MEC, 2008.

BRASIL. Constituição (1988). Constituição da República Federativa do Brasil. Brasília: Senado Federal: Centro Gráfico, 1988.

BRASIL. Ministério da Educação. Secretaria de Educação Básica. Diretrizes Curriculares Nacionais para Educação Básica. Brasília, DF: MEC/SEB, 2013.

BRASIL. Lei 9.394, de 20 de dezembro de 1996. Estabelece as Diretrizes e Bases da Educação Nacional. Brasília, 1996. Disponível em: http://www.planalto.gov.br/ccivil_03/leis/L9394. htm .Acesso em: 13 jun. 2020

CARVALHO, R.P.; CRUZ, D.M. Universidade Corporativa: uma nova estratégia para a aprendizagem organizacional. In: CONGRESSO BRASILEIRO DO ENSINO DE ENGENHARIA - COBENGE, 29., 2001, Porto Alegre. Anais .... Porto Alegre, 2001.

EBOLI, M. Desenvolvimento e alinhamento dos talentos humanos às estratégias empresariais: o surgimento das Universidades Corporativas. São Paulo: Schmukles, 1999.

EBOLI, M. Educação corporativa no Brasil: mitos e verdades. São Paulo: Gente, 2004.

EBOLI, M. et al. Educação Corporativa: fundamentos, evolução e implantação de projetos. São Paulo: Atlas, 2012.

FILATRO, A. et al. DI 4.0: inovação em educação corporativa. São Paulo: Saraiva, 2019.

GIL, A.C. Gestão de pessoas: enfoque nos papéis profissionais. São Paulo: Atlas, 2014.

GROSSI, M.G.R.; COSTA, J.W.; SOUZA, C.B.J. Proposta pedagógica no contexto da educação corporativa. Rev. Temas Educ., v.25 n.2, p.36-55, 2016.

SILVA, M.W.; BALZAN, N.C. Universidade Corporativa: (pré) tendência do ensino superior ou ameaça? Rev. Aval. Educ. Superior, v.12 n.2, 2007.

TARDIF, M. Saberes docentes e formação profissional Petrópolis: Vozes, 2014. 